\title{
High level transgenic expression of soybean (Glycine max) GmERF and Gmubi gene promoters isolated by a novel promoter analysis pipeline
}

\author{
Carlos M Hernandez-Garcia', Robert A Bouchard', Paul J Rushton ${ }^{2,4}$, Michelle L Jones ${ }^{1}$, Xianfeng Chen ${ }^{3,5}$, \\ Michael P Timko², John J Finer ${ }^{1 *}$
}

\begin{abstract}
Background: Although numerous factors can influence gene expression, promoters are perhaps the most important component of the regulatory control process. Promoter regions are often defined as a region upstream of the transcriptional start. They contain regulatory elements that interact with regulatory proteins to modulate gene expression. Most genes possess their own unique promoter and large numbers of promoters are therefore available for study. Unfortunately, relatively few promoters have been isolated and characterized; particularly from soybean (Glycine max).
\end{abstract}

Results: In this research, a bioinformatics approach was first performed to identify members of the Gmubi (G.max

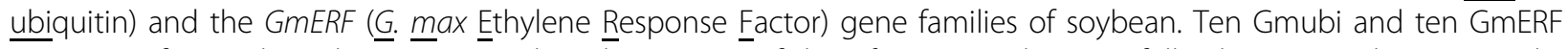
promoters from selected genes were cloned upstream of the gfp gene and successfully characterized using rapid validation tools developed for both transient and stable expression. Quantification of promoter strength using transient expression in lima bean (Phaseolus lunatus) cotyledonary tissue and stable expression in soybean hairy roots showed that the intensity of gfp gene expression was mostly conserved across the two expression systems. Seven of the ten Gmubi promoters yielded from 2- to 7-fold higher expression than a standard CaMV35S promoter while four of the ten GmERF promoters showed from 1.5- to 2.2-times higher GFP levels compared to the CaMV35S promoter. Quantification of GFP expression in stably-transformed hairy roots of soybean was variable among roots derived from different transformation events but consistent among secondary roots, derived from the same primary transformation events. Molecular analysis of hairy root events revealed a direct relationship between copy number and expression intensity; higher copy number events displayed higher GFP expression.

Conclusion: In this study, we present expression intensity data on 20 novel soybean promoters from two different gene families, ubiquitin and ERF. We also demonstrate the utility of lima bean cotyledons and soybean hairy roots for rapid promoter analyses and provide novel insights towards the utilization of these expression systems. The soybean promoters characterized here will be useful for production of transgenic soybean plants for both basic research and commercial plant improvement.

\section{Background}

With the increasing amount of biological information derived from genome sequencing projects of several plant species [1,2], opportunities exist for functional analysis of those sequences using a combination of computational approaches and various methods of wet

\footnotetext{
* Correspondence: finer.1@osu.edu

'Department of Horticulture and Crop Science, OARDC/The Ohio State

University, 1680 Madison Ave., Wooster, OH 44691 USA

Full list of author information is available at the end of the article
}

laboratory analyses of gene expression. The recent release of the soybean genome [3] has tremendously facilitated computational genome-wide analyses of the soybean genome and identification of specific DNA sequences, which need to be validated using functional analysis tools. The availability of the soybean genome has also provided unprecedented access to sequences for a wide range of promoters from diverse gene families, which will lead to a better understanding of the regulation of gene expression and the discovery of novel 
soybean promoters for use in basic research and applied crop biotechnology.

Promoters are the primary regulators of gene expression at the transcriptional level and are key to controlling transgenes in transgenic organisms [4]. The use of one or only a few different promoters to direct expression of different genes in transgene stacks can lead to homology-based gene silencing and unpredictable transgene expression in transgenic plants [5]. Consequently, it is absolutely necessary to increase the availability of different promoters for plant transformation. Although the constitutive highly-expressed Cauliflower Mosaic Virus 35S (CaMV35S) promoter is commonly used for gene regulation in plants, different plant genomes can provide additional useful native plant promoters ranging from highly-expressing constitutive to tissue-specific and inducible. Likewise, analyses of native promoters will most likely reveal a large variety of heretofore undiscovered cis-regulatory elements, which will increase our understanding of gene expression regulation [6]. Although several plant promoters are available as an alternative to the CaMV35S promoter, very few soybean promoters have been isolated and extensively characterized in soybean [7-9], in spite of the world-wide economic impact of this crop.

We recently reported the isolation and characterization of a Glycine max polyubiquitin (Gmubi) promoter, which leads to high constitutive levels of both transient [10] and stable gene expression in various tissues of transgenic soybeans [7]. Other plant ubiquitin promoters have also been isolated and characterized in a wide variety of plant species [4]. Particularly, ubiquitin promoters from rice [11] and maize [12] have been extensively characterized and frequently used in both basic research and in the production of commercial transgenics. Ubiquitin promoters typically drive strong constitutive gene expression, which is especially high in young tissues, vascular tissues and pollen [13]. The enhancement of gene expression from the presence of the leading intron in the different ubiquitin promoters has also received considerable attention [14]. In spite of the emphasis on the use of ubiquitin promoters, most studies to date have relied on single promoter sequences isolated from different plant species [15-17]. However, the ubiquitin gene family is quite large in most plants and isolation and characterization of different ubiquitin promoters, from the same plant, could serve as a source of additional promoters and provide useful information on how different ubiquitin genes are differentially regulated.

As ubiquitin promoters tend to drive constitutive gene expression, additional promoter sequences from inducible genes may also be of interest [18]. The Ethylene Response Factor (ERF) gene family encodes a large group of transcription factors characterized by the presence of a single AP2/ERF domain [19]. ERF proteins play important roles in ethylene-mediated gene transcription [20] and in a wide range of biotic and abiotic stress responses such as pathogen attack [21], drought tolerance, salt tolerance and low temperatures $[22,23]$. The ERF genes therefore could be excellent sources for inducible promoters, which most likely contain interesting cis-regulatory elements within their sequences.

Promoter characterization typically involves the introduction and analysis of DNA constructs containing promoters fused to a reporter gene. Temporal and tissue-specific expression of the reporter gene can then be directly observed and quantified in transgenic plant tissues. Although soybean transformation was first reported many years ago [24-26], it remains consistent but inefficient [27] and it may not be entirely suitable for medium- to high-throughput analysis of soybean promoters. Due to this limitation, analyses of soybean promoters and their cis-regulatory elements are often performed using heterologous plant expression systems such as Arabidopsis and tobacco [9,28,29]. Analyses using heterologous systems have value but validation of soybean promoters in soybean $[7,8]$, or at least in another member of the Fabaceae family, is preferred as heterologous systems may not accurately reflect promoter strength and specificity [30-32].

For rapid analysis of promoters, transient gene expression offers many advantages and some disadvantages compared with the use of stably-transformed tissues. Transient expression can be detected as early as $2 \mathrm{~h}$ post DNA introduction in soybean tissues [33], which is quite useful for rapid estimation of promoter activity. Depending on the method for DNA introduction [34], different tissue types can be targeted for gene delivery, allowing increased flexibility in construct evaluations. In our laboratory, transient expression has been successfully used for evaluation of soybean promoter variants [10], but these evaluations were performed using lima bean (Phaseolus lunatus) cotyledons. Transient expression analysis for promoter validation using soybean cotyledons as an alternate target to lima bean cotyledons has not been previously reported.

For evaluation of constructs in stably-transformed soybean tissues, the production of hairy roots provides the most rapid and efficient method for generation of transgenic soybean tissues. Soybean hairy root cultures induced by Agrobacterium rhizogenes have been successfully used for rapid analysis of soybean cyst nematode infestation [35], improvement of genetic transformation efficiencies [36] and analysis of phenolic metabolism $[28,37]$. As an alternate approach, composite plants [38] consisting of hairy roots on non-transgenic shoots are also useful for rapid evaluation of gene expression in 
stably transformed soybean tissues [39]. Previous molecular analyses conducted on soybean hairy roots have revealed the presence of high copy number integrations $[35,36,38]$, although the relationship between high copy number insertions and gene expression in hairy roots has not been reported.

With the aim of discovering unique and useful soybean promoters with potential applications in both basic research and crop improvement, we here identify, clone and validate 20 novel soybean promoters from the $u b i$ quitin and ERF gene families. We present two different and complementary promoter validation tools based on transient expression in lima bean cotyledons and production of stably-transformed soybean hairy roots. Quantitative gene expression analysis of these 20 new soybean promoters using 2 different promoter validation tools allows us to greatly expand the toolbox of available soybean promoters.

\section{Results}

\section{Phylogenetic analysis of the Gmubi and GmERF genes}

Phylogenetic analyses of the gene models in the soybean genome revealed at least 46 genes whose predicted amino acid sequences contained at least one ubiquitin- coding unit (Additional file 1). Of these, 25 genes were similar to the ubiquitin gene family that includes Gmubi1-10 (Figure 1a). The other 21 genes contained a lower number of ubiquitin-like coding units more similar to those found in other proteins such as the apoptotic regulator Scythe and the adaptor molecule RAD23 [40,41]. The Gmubi1-9 genes all belong to the same polyubiquitin-containing family; whereas, the Gmubi10 gene belongs to a different, small monoubiquitin-containing subfamily (Figure 1a).

Phylogenetic analyses of the ERF/AP2 genes from soybean revealed a total of 371 genes, which could be annotated as AP2/ERF genes (Additional file 2). Of these, 12 genes were not incorporated into the phylogenetic tree as they were either too divergent or incorrectly predicted (Glyma01g22260.1, Glyma02g11060.1, Glyma05g07840.1, Glyma08g24110.1, Glyma11g05450.1, Glyma14g00600.1, Glyma15g25120.1, Glyma17g17010.1, Glyma18g01030.1, Glyma19g43260.1, Glyma19g43260.2, Glyma19g45390.1). A total of 359 ERF/AP2 genes were retained, including the ten chosen for this study. The soybean AP2/ERF family is broadly similar to that from other higher plant species and can be subdivided into the ERF and AP2 subfamilies (Figure 1b). Similar to Arabidopsis [19] and

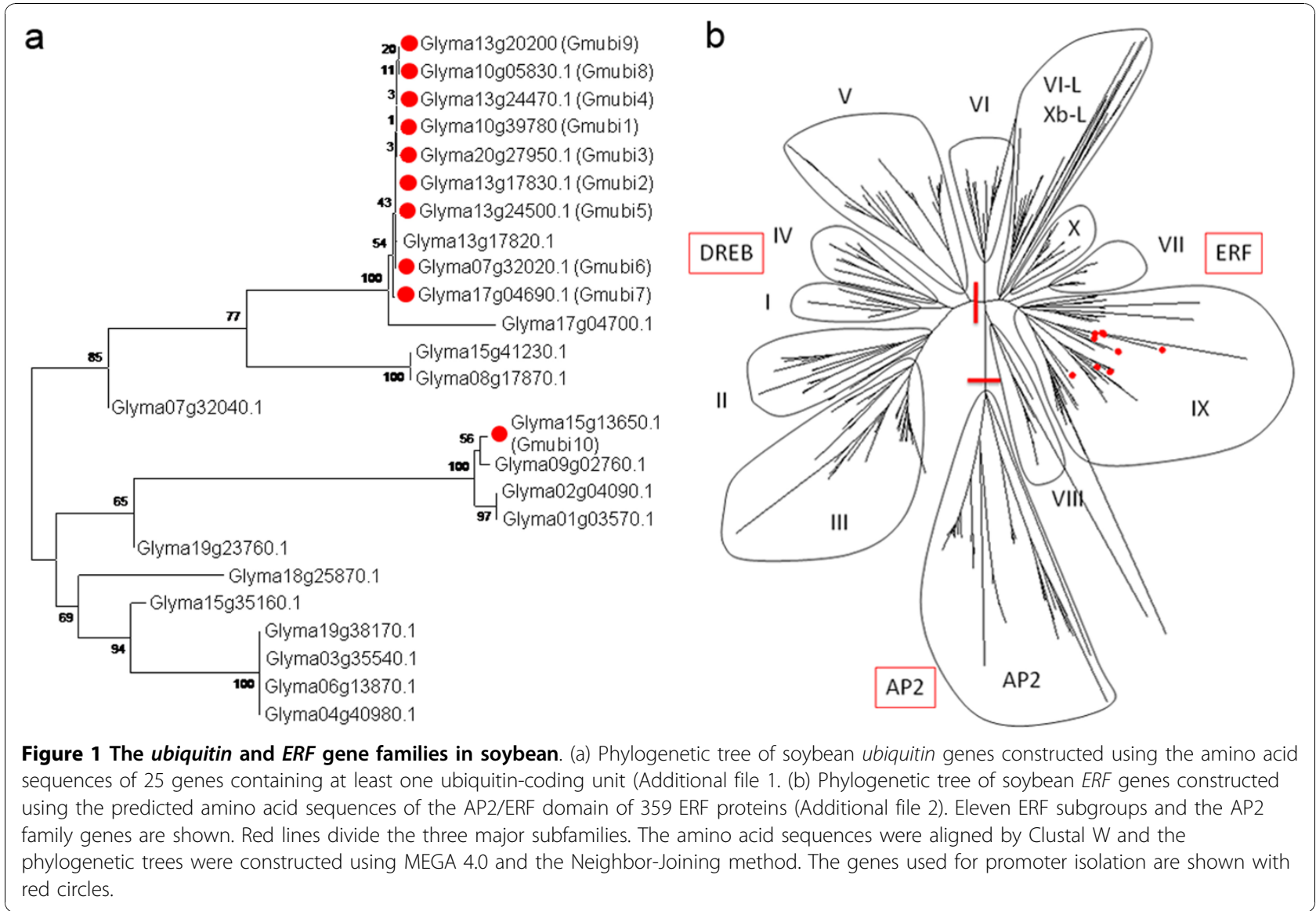


tobacco [42], the ERF family could be further subdivided into the DREB (groups I-V) and the ERF subfamilies (groups VI-X). One additional subfamily was apparent and may be related to the members of group VI-L and $\mathrm{Xb}-\mathrm{L}$ as these proteins were omitted from both the Arabidopsis and tobacco analyses. This phylogenetic analysis provides a framework for the study of promoters from other members of the soybean AP2/ERF multigene family and illustrates the phylogenetic positions of the 10 group IX GmERF genes used for promoter isolation in this study. The GmERF1-10 genes were chosen as they are likely to be wound-and/or jasmonate-inducible based on their phylogenetic position [42].

\section{Evaluation of soybean and lima bean cotyledons for transient expression analysis}

Transient gene expression in soybean and lima bean cotyledons was conducted and compared with the initial aim of developing a soybean-based transient expression system for validation of soybean promoters. Introduction of the 35S-GFP construct into soybean cotyledons resulted in relatively high levels of gene expression, followed by a very rapid decline (Figure 2). In soybean, the GFP appeared to diffuse from the targeted cells into the surrounding cells a few hours after bombardment. GFP was minimally detected using our automated image collection system $\sim 48 \mathrm{~h}$ after bombardment (Figure 2a). Time-lapse animations of GFP expression tracked for $100 \mathrm{~h}$ in bombarded soybean cotyledons clearly showed the rapid loss of GFP in the primary targeted cells and the apparent diffusion to the surrounding cells (Additional file 3). In contrast, in lima bean cotyledonary cells, transient GFP expression modulated by the 35S-GFP construct appeared to remain localized in single cells (Figure $2 \mathrm{~b}$ ) and time-lapse animations revealed that GFP was visible for over $100 \mathrm{~h}$ (Additional file 3). Confocal microscopy of soybean cotyledonary cells, conducted $10 \mathrm{~h}$ after bombardment with the 35S-GFP plasmid confirmed high levels of GFP in the cytoplasm and nuclei of the main targeted cells, but also low levels of GFP in the cytoplasm and nuclei of the adjacent cotyledonary cells (Figure 3 ). Confocal microscopy also confirmed restriction of GFP to the main

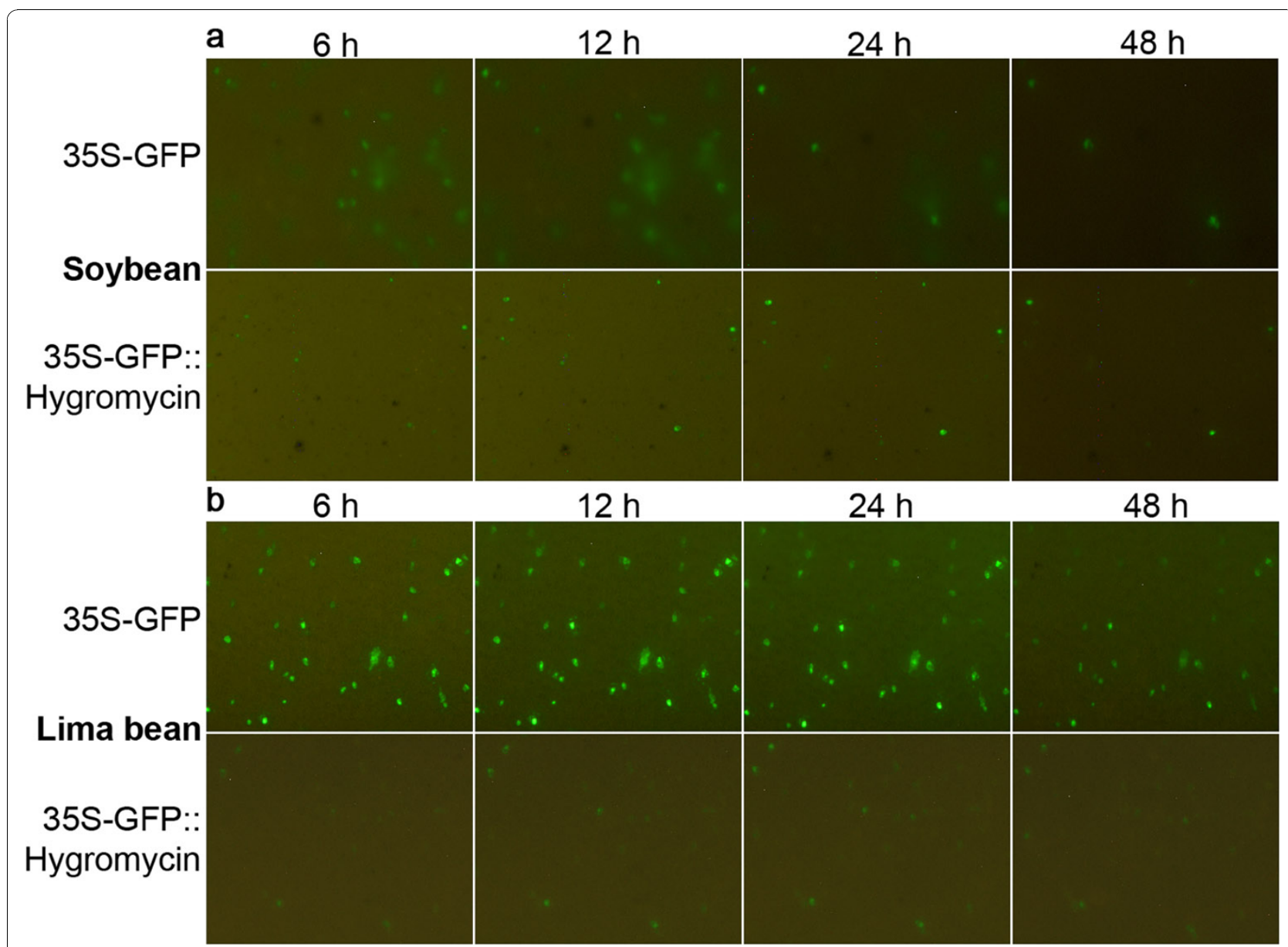

Figure 2 Transient GFP expression using soybean and lima bean cotyledons. Soybean cotyledons (a) and lima bean cotyledons (b) were transformed with 35S-GFP [10] and 35S-GFP::Hygromycin [43] plasmids. Numbers on top represent hours (h) after bombardment. 


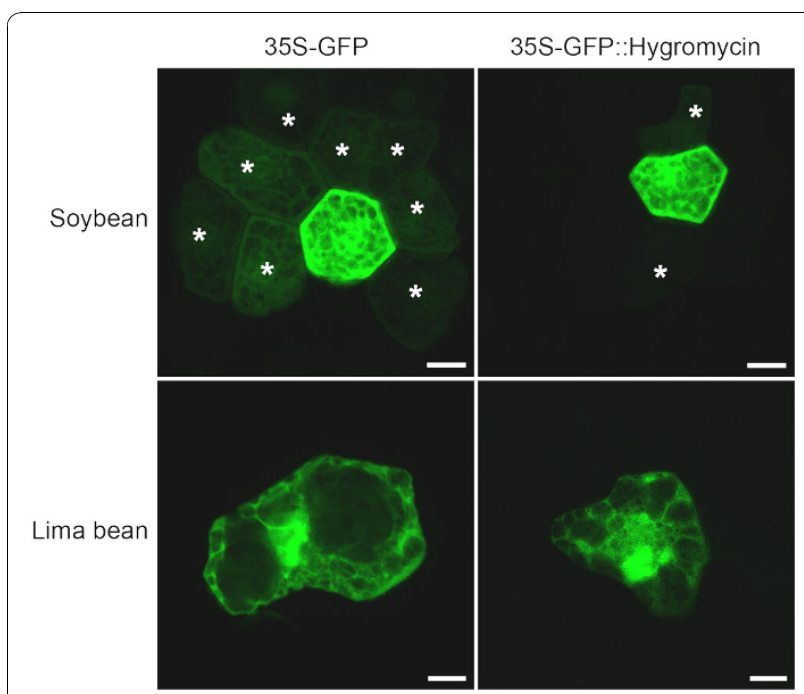

Figure 3 Confocal microscopy of GFP expression in bombarded soybean and lima bean cotyledons. The analysis was performed $10 \mathrm{~h}$ after DNA introduction. The 35S-GFP and 35S-GFP.:Hygromycin plasmids were previously described by Chiera et al [10] and Chiera et al [43], respectively. Asterisks mark GFP-expressing cells adjacent to single transformed cells. Bars are equivalent to $10 \mu \mathrm{m}$. targeted cell in bombarded lima bean cotyledonary tissues (Figure 3). This analysis also revealed basic differences in cotyledon cell morphology between lima bean and soybean. For example, soybean cotyledonary cells were considerably smaller and more regularly-shaped than lima bean cells and contained smaller vacuoles (Figure 3).

To investigate if the apparent GFP diffusion visualized in soybean cotyledonary cells was related to the small size of GFP, a translational fusion of GFP::Hygromycin [43] was introduced into both soybean and lima bean cotyledons. Although GFP levels and the numbers of GFP-expressing cells were considerably lower than obtained earlier with the 35S-GFP introduction, GFP expression from the translational fusion remained in the targeted cells longer in both plants and was detected until over $100 \mathrm{~h}$ after transformation (Figure 2a-b and data not shown). Confocal microscopy of soybean cotyledons, bombarded with the GFP::Hygromycin translational fusion confirmed strong GFP expression in the cytoplasm and nuclei of targeted cells but a clear reduction of GFP levels in the adjacent cells (Figure 3). Confocal analysis of lima bean cotyledons showed high levels of

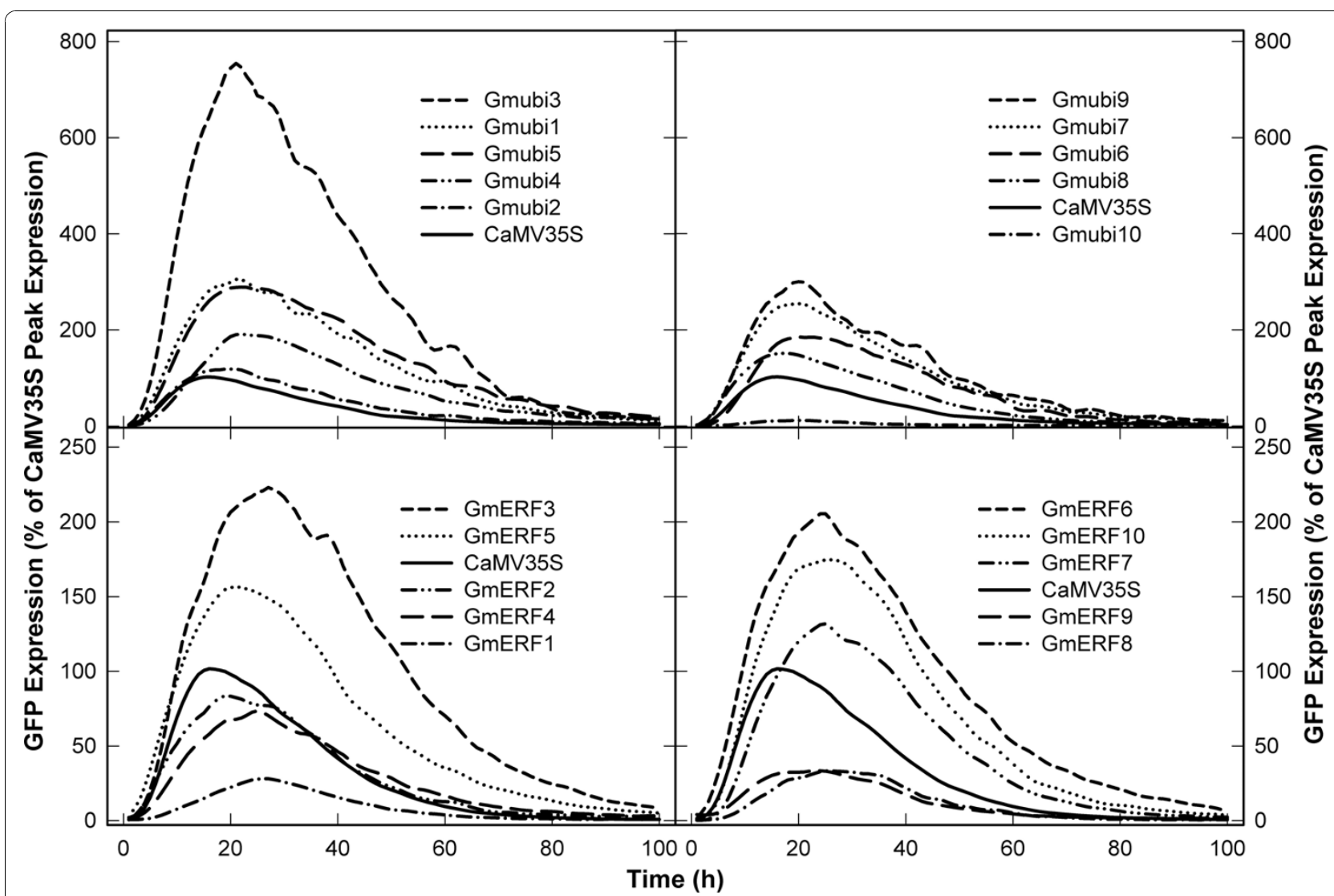

Figure 4 Profiles of transient GFP expression driven by the Gmubi and GmERF promoters. Images were collected every hour for $100 \mathrm{~h}$ and GFP quantified using ImageJ. GFP expression levels for each promoter are reported as the percent of peak GFP expression obtained with the CaMV35S promoter. 
GFP in the cytoplasm and nuclei of targeted cells and no detectable GFP levels in the adjacent cells (Figure 3).

\section{Transient expression analysis of promoters using lima bean cotyledons}

The upstream regions of gene coding sequences for 10 Gmubi and 10 GmERF genes (Figure 1) were cloned 5' to the $g f p$ gene and rapidly characterized. Profiles of transient GFP expression were generated for all 20 soybean promoters, along with the CaMV35S promoter, using lima bean cotyledons as target tissue (Figure 4). GFP expression was first detectable in cotyledonary cells 2-3 $\mathrm{h}$ after DNA introduction and became almost undetectable with our automated image collection and analysis system [44] $\sim 100 \mathrm{~h}$ after DNA delivery.

The transient expression profiles were mostly similar for all the Gmubi promoters regardless of promoter strength. However, GFP expression peaks for the strong Gmubi promoters appeared to be reached later than the low-expressing promoters or the CaMV35S promoter. Most of the Gmubi promoters gave rise to exceptionally high levels of transient GFP expression based on a comparison to the CaMV35S promoter; the y-axis in Figure 4 is the percent of peak CaMV35S expression. The Gmubi1, Gmubi3, Gmubi4, Gmubi5, Gmubi6, Gmubi7 and Gmubi9 promoters displayed a $\sim 2$-7-fold increase in expression over levels obtained with the CaMV35S promoter (Figure 4). The Gmubi2 and Gmubi8 promoters showed similar levels of transient GFP expression compared with the CaMV35S, while use of the Gmubi10 promoter resulted in very low levels of GFP expression.

The transient expression profiles generated for the GmERF promoters also showed a range of promoter strengths but reasonable consistency in the timing of peak expression (Figure 4). The times for peak GFP expression driven by the GmERF promoters were more variable than those observed for the Gmubi promoters but were consistently later than CaMV35S-driven GFP peak (Figure 4). Although many of the GmERF promoters resulted in lower GFP levels than the Gmubi promoters, some gave higher expression than the CaMV35S promoter. The GmERF3, GmERF5, GmERF6, and GmERF10 promoters exhibited 1.5-2.2-times higher GFP levels compared to the CaMV35S promoter. The GmERF2, GmERF4 and GmERF7 promoters showed similar GFP levels to CaMV35S, while GmERF1, GmERF8 and GmERF9 promoters gave rise to lower levels of transient GFP expression (Figure 4).

\section{Stable expression analysis using soybean hairy roots}

In addition to analysis of promoter activity using transient expression, promoter strength was assessed in stably-transformed soybean hairy roots. One week after $A$. rhizogenes-inoculation of soybean cotyledons, numerous small cell clusters composed of both GFP- and non GFP-expressing cells were evident in the wounded sites located on the abaxial side of the inoculated cotyledons. Approximately two weeks after inoculation, the cotyledons formed numerous roots, which were $72 \%$ GFPpositive (Table 1). Although the clear majority of GFPexpressing root events appeared to express GFP homogeneously, formation of chimeric roots was occasionally observed. Most hairy roots were relatively prolific and grew quickly following subculture to fresh OMS medium. Secondary roots could be excised and used to generate additional clonal tissues for analysis.

The intensities of GFP expression mediated by the soybean promoters and a CaMV35S promoter construct in soybean hairy roots were determined using image analysis. Many of the Gmubi promoters gave rise to significantly higher levels of GFP expression than the CaMV35S promoter used as a control (ANOVA, P > 0.0001 , Figure 5a). The strongest Gmubi promoters (Gmubi1, Gmubi2, Gmubi3, Gmubi4, Gmubi7 and Gmubi9) showed a 2-4-fold increase in GFP expression over levels given by the CaMV35S promoter (Figure $5 \mathrm{a}$ ). The Gmubi5, Gmubi6 and Gmubi8 promoters gave rise to similar or slightly higher levels of GFP than the CaMV35S promoter, while the Gmubi10 promoter showed the lowest GFP expression among the Gmubi promoters.

The GmERF promoters displayed somewhat lower GFP intensities in hairy roots than the Gmubi promoters but some of these promoters displayed higher expression levels than the CaMV35 promoter (ANOVA, $\mathrm{P}>0.0001$, Figure 5b). The GmERF2, GmERF6 and GmERF10 promoters showed 1.4-1.7-times higher GFP than CaMV35S (Figure 5b). The GmERF3, GmERF4 and GmERF7 promoters exhibited similar GFP compared to the CaMV35S promoter; whereas the GmERF1, GmERF5, GmERF8 and GmERF9 promoters directed lower levels of GFP compared to the CaMV35S promoter.

Although the average GFP expression levels were determined based on image analysis of different soybean hairy root events, an unexpected large variation in GFP intensities among different root events was observed for all of the promoters evaluated, including the CaMV35S promoter. As a result of this large variation, the standard deviations for GFP intensity means were quite

Table 1 Average of primary hairy roots expressing GFP mediated by promoter constructs

\begin{tabular}{ccc}
\hline Number of roots analyzed & \multicolumn{2}{c}{ GFP expression } \\
\cline { 2 - 3 } & Positive (+) & Negative (-) \\
\hline 195 & $140(72 \%)$ & $55(28 \%)$ \\
\hline
\end{tabular}


large for most of the promoters (Figure 5a-b). Analysis of GFP expression in numerous secondary roots from the same primary root event was performed using events containing the Gmubi3, GmERF3 and GmERF10 promoters. Although a large variation in GFP intensities was seen among primary roots, the variation in GFP intensity was much smaller in the secondary roots generated from single primary roots (Figure 6a). A remarkable reduction of the standard deviations for GFP intensity means in secondary roots was also apparent (Figure 6b).

\section{Southern hybridization analysis}

With the aim of studying the transgene integration patterns present in the soybean transgenic hairy roots and

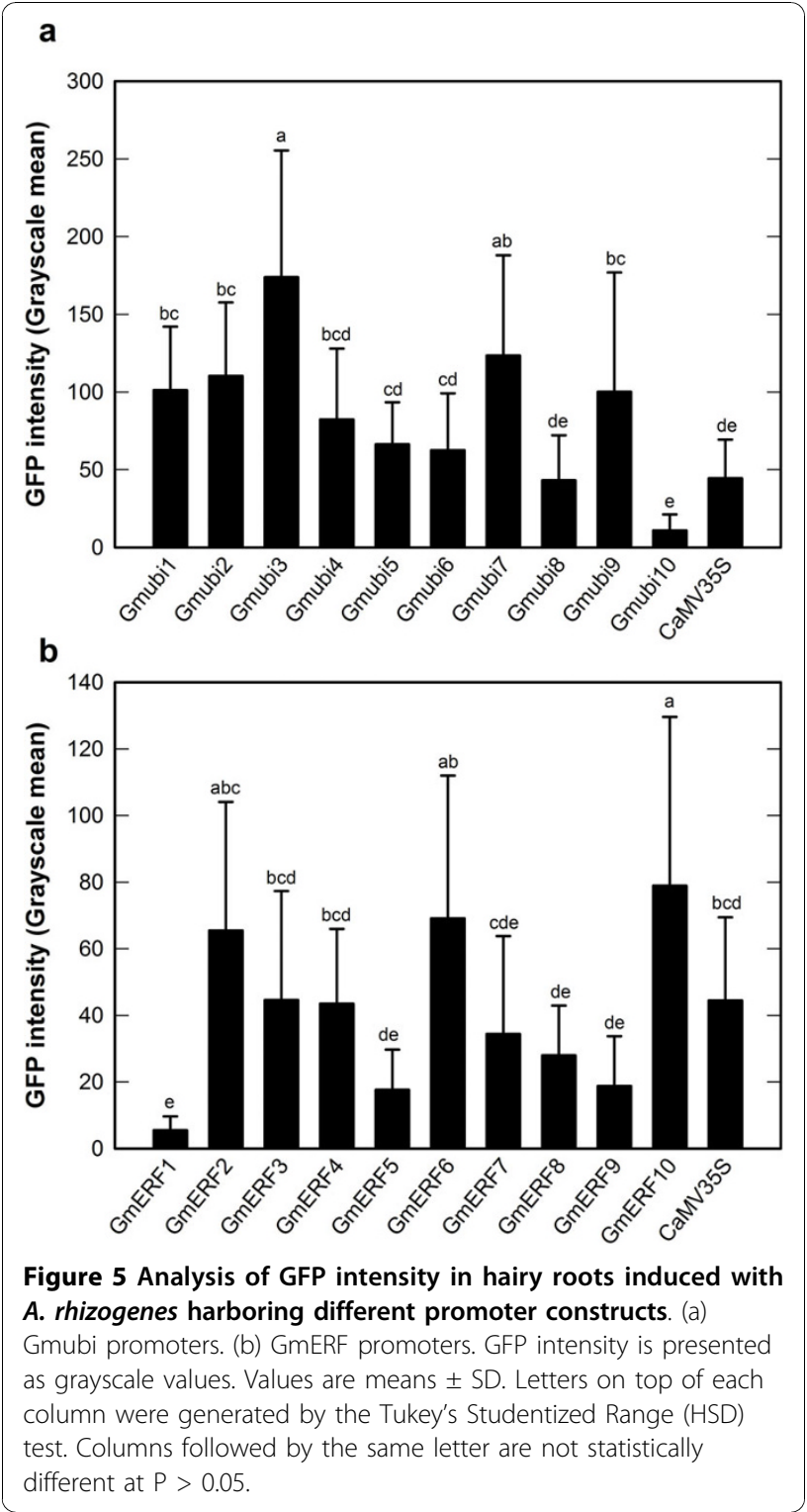

determining if a relationship existed between GFP intensity and transgene copy number, Southern hybridization analysis was conducted on genomic DNA isolated from either GmERF6- or GmERF10-containing hairy roots using the $g f p$ coding region as the hybridization probe. Hybridization signals were detected in all the transformed hairy root lines analyzed (Figure 7), confirming the stable integration of the $g f p$ coding sequence in the genomes. The lanes containing DNA from hairy roots induced with $A$. rhizogenes harboring no binary vector, showed no hybridization bands (lanes: Williams82, Figure 7). As BsrGI recognizes a single site within the T-DNA of pCAMBIA-promoter constructs, the presence of one to seven variable-size bands in the genomic DNA from either GmERF6- or GmERF10-containing roots indicates T-DNA integrations ranging from one to seven copies (Figure 7).
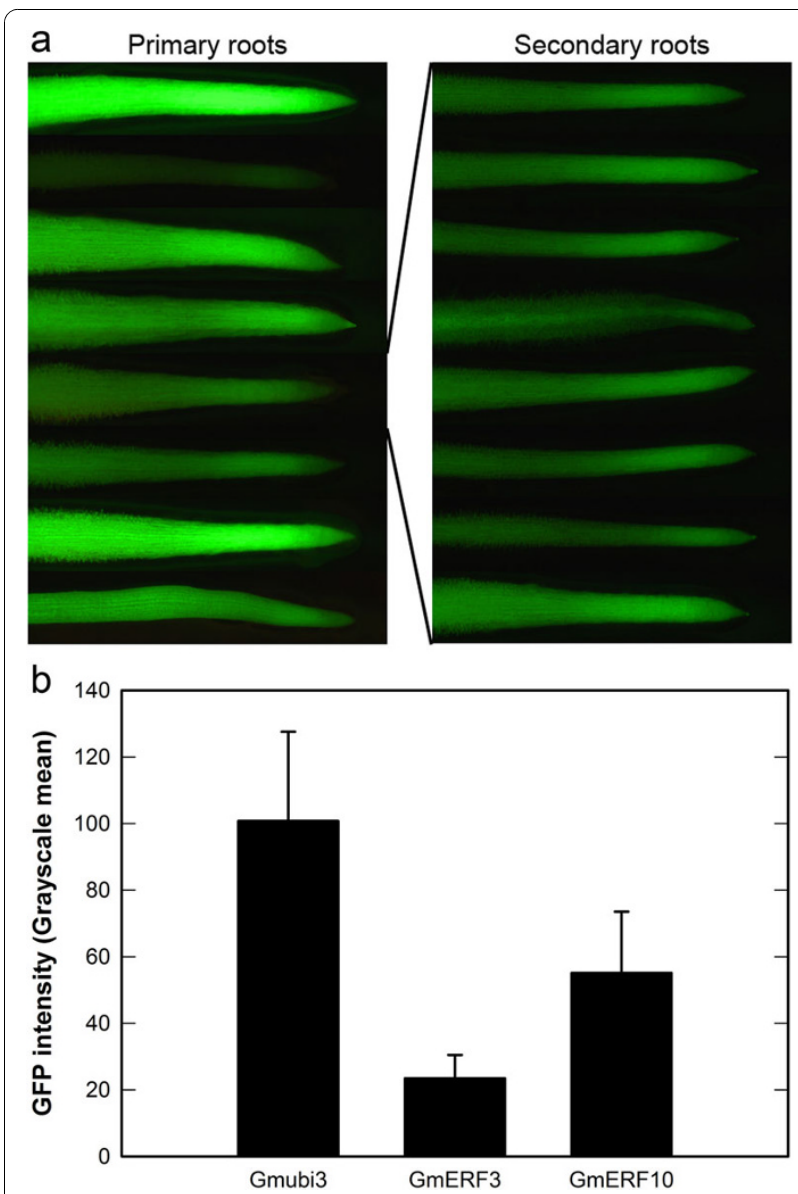

Figure 6 GFP expression variation among independent hairy root events and within events. (a) Primary roots containing the GmERF10 promoter and secondary hairy roots generated from a single GmERF10-containing primary root. (b) GFP intensity quantification in secondary hairy roots generated from single primary roots containing either the Gmubi3, GmERF3 or GmERF10 promoter. Values are means \pm SD 


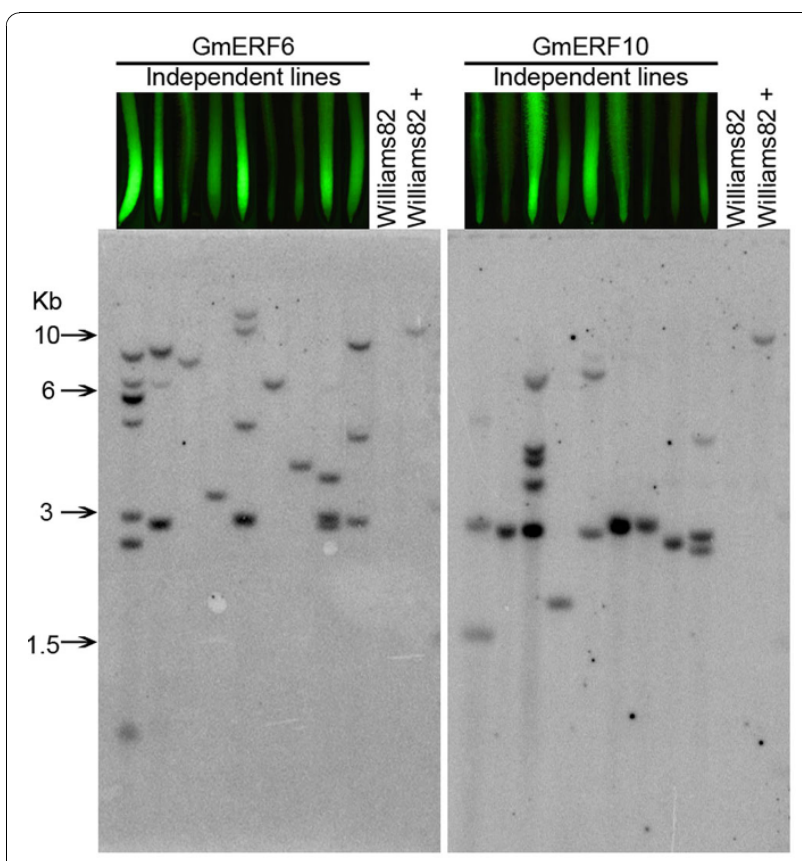

Figure 7 Southern blot analysis of genomic DNA from hairy roots. Images of root tips on top of lanes correspond to independent root events used for DNA extraction. DNA was digested with $\mathrm{Bs} r \mathrm{Gl}$ and hybridized with a ${ }^{32} \mathrm{P}$-labeled gfp probe. "Williams82" is DNA from roots induced with A. rhizogenes harboring no promoter construct, "Williams $82+$ " is Williams82 DNA plus 10 pg of respective plasmid, representing a single transgene copy in the soybean genome.

Transgene copy number from the southern hybridization analysis was also directly correlated with the GFP expression intensity displayed in the transgenic hairy roots that were used for genomic DNA extraction (Additional file 4). Hairy root events with high transgene copy number generally displayed high GFP intensities; whereas, hairy roots events with single or low T-DNA copy number gave low or moderate GFP intensities.

\section{Discussion}

\section{Bioinformatics analysis of the Gmubi and GmERF gene families of soybean}

The polyubiquitin gene family in soybean (Figure 1A) contains three moderately well characterized genes (Gmubi1, Gmubi2 and Gmubi3); however, other family members have received little to no attention. The promoters regulating these genes have likewise not been well characterized but show promise as strong constitutive promoters based on recently-reported transcriptome data $[45,46]$ and previous characterizations of a soybean polyubiquitin promoter (Gmubi) $[7,10]$ that was recloned in this current research as a slightly longer promoter and renamed "Gmubi3".

The ERF genes were classified based on their coding sequences, and particularly on the presence of the well-conserved AP2/ERF DNA-binding domain [19]. The phylogeny of GmERF genes in this study (Figure 1b) was very similar to phylogenies previously reported for ERFs in rice, Arabidopsis and tobacco [19,42,47], confirming that this family of transcription factor is quite conserved among different plants. A previous phylogenetic analysis of GmERF genes revealed the presence of 98 unigenes containing a complete AP2/ERF domain in soybean [47]; however, we here report 359 AP2/ERFcontaining GmERF genes using data from the recently released soybean genome assembly, representing a significant update for this gene family in soybean.

\section{Transient expression assays in soybean and lima bean cotyledons}

Quantitative characterization of soybean promoters was rapidly assessed using both transient gene expression in lima bean cotyledons and stable expression in soybean hairy roots. We have previously reported the use of lima bean cotyledons for rapid analyses of transient gene expression [10] and characterization of viral suppressors of gene silencing $[43,48]$. In this report, we also evaluate soybean cotyledons as a potential target tissue for rapid validation of soybean promoters. In soybean cotyledons, initial attempts to visualize GFP at the 24 hour time point, which is the peak expression time for the lima bean target [10], were unsuccessful as only very low levels of GFP were observed. However, use of our automated image collection system [44] for semi-continuous monitoring of GFP expression revealed that the GFP protein apparently diffused rapidly from the initial target cell in soybean cotyledons, leading to depletion of scorable GFP levels (Figure 2, Additional file 3). In lima bean cells, rapid diffusion of GFP was not detected in the cells surrounding the original targeted cell, although it may occur at reduced levels. The loss of the GFP protein observed using soybean cotyledons suggests that there are basic differences in the epidermal cell structures in lima beans and soybeans. Confocal microscopy indeed confirmed some major differences in the anatomy of epidermal cells (Figure 3).

Retention of GFP in the targeted cells after bombardment is definitely preferable for gene expression analysis. The rapid loss of GFP in soybean cotyledonary cells made analysis difficult and this target tissue is completely unsuitable for transient expression analysis using single time point determinations. The presence of small amounts of GFP at the $24 \mathrm{~h}$ time point could be misinterpreted as the absence of expression, which was not the case. Since single time point determinations at $24 \mathrm{~h}$ are often used for transient expression analysis using GFP [33] and GUS [49], loss of transient gene expression as reported here in soybean cotyledonary tissues should be recognized as a potential problem in 
interpreting results. The use of dynamic semi-continuous monitoring of gene expression using our automated image collection system facilitated the detection of GFP loss from targeted cells, and movement into the surrounding cells. Without semi-continuous monitoring, movement of GFP may not have been perceived.

Transient expression of GFP in cells of lima bean cotyledons was far more consistent over time compared to soybean cotyledons (Figure 2). Lima bean cotyledons therefore offer a more suitable target tissue for quantitative transient GFP expression assays. Loss of GFP from the targeted soybean cotyledonary cells was somewhat reduced through the use of a translational fusion of GFP to the hygromycin resistance gene (Figure 2, 3), resulting in production of a larger fusion protein. However, use of this translational fusion resulted in much lower apparent GFP intensities and fewer foci (Figure 2 lower panels). We have previously reported that translational fusions containing GFP give rise to considerable reductions of transient GFP intensities in lima bean cotyledonary cells, probably due to either a quenching of fluorescence by the protein partner or conformational changes in GFP as a result of an alteration of the chromophore structure $[43,48]$. Although use of translational fusions can be used to minimize loss of the small GFP protein from certain target tissues, the effects of the fusion partner on GFP detection need to be considered when this approach is utilized.

\section{Transient expression mediated by Gmubi and GmERF promoters}

In this study, the Gmubi1-9 promoters were isolated from polyubiquitin genes sharing high homology (Figure 1a) but containing variable numbers of the ubiquitincoding unit [50]. The Gmubi1, Gmubi2, Gmubi3 and Gmubi8 contained 4 ubiquitin-coding units; the Gmubi4 and Gmubi6 contained 7 ubiquitin-coding units; and the Gmubi5, Gmubi7 and Gmubi9 contained 6, 5 and 2 ubiquitin-coding units, respectively. The Gmubi10 promoter was isolated from a more distant relative gene containing a monomeric ubiquitin-coding unit (Figure 1a). Although the Gmubi1-9 promoters gave rise to relatively high levels of gene expression, the Gmubi10 promoter displayed consistently low expression levels in both transient expression and hairy roots. All of the reports to date describing ubiquitin promoters in different plants have focused on polyubiquitin gene promoters $[10,15,51]$.

The Gmubi promoters characterized here were either intron-containing or intron-less promoters. The Gmubi1-7 gene sequences contained predicted introns in the 5'-UTR, which were predicted to splice to acceptor sites generated during promoter cloning just prior to the initiation codon of the $g f p$ coding sequence. The
Gmubi8-10 gene sequences contained no predicted introns in the 5'-UTR. To our knowledge, no characterization of native intron-less plant ubiquitin promoters has been previously reported. Although in this study there were no evident differences between transient GFP expression levels mediated by the intron-containing or the intron-less Gmubi promoters, the introns within the 5'UTR of most polyubiquitin promoters quantitatively enhance transgene expression levels $[51,52]$.

Although most of the Gmubi promoters directed overall high expression levels, the Gmubi3 promoter gave exceptionally high levels of GFP expression. This high gene expression driven by the Gmubi3 promoter is not surprising as the Gmubi3 gene is highly active in different organs of soybean $[45,46]$. We previously reported 5-fold greater transient GFP expression using a slightly truncated version of the Gmubi3 promoter (917 bp; Gmubi) compared to a CaMV35S promoter [10]. In the present study, the Gmubi3 promoter (1438 bp) gave rise to 7-fold greater transient GFP expression compared to the same CaMV35S promoter. We have also reported that removal of the intron from the 5'UTR of the Gmubi promoter resulted in much lower levels of both transient expression in lima bean cotyledons [10] and stable expression in transgenic soybeans [7]. Although the intensity of expression was altered by the removal of the intron from the 5'UTR of the Gmubi promoter, the pattern of expression remained the same. Collectively, these results indicate that the intronic and upstream regions of this promoter may contain important cis-regulatory elements responsible for high levels of expression. An in-depth functional analysis of the Gmubi3 promoter may allow the identification of specific promoter elements that lead to this high gene expression.

The transient expression profiles from the GmERF promoters (Figure 4) were similar regardless of promoter strength. However, the time of peak GFP expression for the different GmERF promoters was more inconsistent compared to the expression peaks for the Gmubi promoters. This variability in expression peaks among the GmERF promoters may be associated with the transcriptional regulation of ERF genes under conditions of stress [22,23].

The GmERF promoters characterized in the present study were isolated from group IX GmERF genes (Figure 1b), which share high homology with group IX tobacco ERF genes [42]. Transcription of group IX ERF genes in tobacco and soybean can be induced after wounding or exogenous application of methyl jasmonate (MeJa) $[42,47]$. Particularly, a group IX soybean ERF gene (GmERF69), with high similarity to the GmERF10 gene sequence identified here (Table 2), displayed high expression levels in soybean seedlings after exogenous application of MeJa, ethylene and salicylic acid, or 
Table 2 Gene IDs for Gmubi and GmERF genes and the respective sizes of their isolated promoters

\begin{tabular}{llllll}
\hline \multicolumn{3}{c}{ Gmubi promoters } & \multicolumn{3}{c}{ GmERF promoters } \\
\hline Promoter & $\begin{array}{l}\text { Size } \\
\text { (bp) }\end{array}$ & Gene ID & Promoter & $\begin{array}{l}\text { Size } \\
\text { (bp) }\end{array}$ & Gene ID \\
\hline Gmubi1 & 1449 & Glyma10g39780 & GmERF1 & 1171 & Glyma20g16920.1 \\
Gmubi2 & 1484 & Glyma13g17830.1 & GmERF2 & 1243 & Glyma20g16910.1 \\
Gmubi3 & 1438 & Glyma20g27950.1 & GmERF3 & 1331 & Glyma11g03900.1 \\
Gmubi4 & 1430 & Glyma13g24470.1 & GmERF4 & 1137 & Glyma01g41530.1 \\
Gmubi5 & 1452 & Glyma13g24500.1 & GmERF5 & 1166 & Glyma05g05180.1 \\
Gmubi6 & 1409 & Glyma07g32020.1 & GmERF6 & 1257 & Glyma05g05130.1 \\
Gmubi7 & 1453 & Glyma17g04690.1 & GmERF7 & 1310 & Glyma19g43820.1 \\
Gmubi81 & 892 & Glyma10g05830.1 & GmERF8 & 967 & Glyma20g34570.1 \\
Gmubi9 & 1314 & Glyma13g20200 & GmERF9 & 1125 & Glyma10g33060.1 \\
Gmubi10 & 1355 & Glyma15g13650.1 & GmERF10 & 1196 & Glyma17g15460.1 \\
\hline
\end{tabular}

'The Gmubi8-10 promoters do not contain intron sequences within their 5'UTR.

${ }^{2}$ The Gmubi10 promoter was isolated from a monoubiquitin gene containing a monomeric ubiquitin-coding unit.

growth under cold and salt conditions [47]. As gene transcription is largely regulated by cis-acting regulatory elements within the promoter sequences [53], the promoters from the group IX GmERF genes may be good candidates to direct inducible transgene expression. Further in-depth functional characterization of the GmERF promoters validated herein along with their potential cis-regulatory elements may also be of particular interest to increase the current knowledge of gene transcription regulation under various stress conditions.

\section{Gene expression mediated by Gmubi and GmERF promoters in hairy roots}

The percentage of GFP-positive hairy roots achieved here $(72 \%$, Table 1$)$ is substantially higher than previously reported for $A$. rhizogenes-induced hairy roots of soybean (50\%) [38]. The development of the hairy root phenotype caused by $A$. rhizogenes is the result of the integration and expression of T-DNA contained in the bacterial root inducing (Ri) plasmid in the plant genome [54]. A. rhizogenes can also transfer the T-DNA from binary vectors, leading to the formation of hairy roots with or without the binary vector T-DNA. The ratios of hairy roots with and without the binary vector T-DNA can vary tremendously across different plants [38].

GFP detection and analysis in hairy roots was relatively straightforward as hairy roots do not contain chlorophyll, which can otherwise interfere with GFP detection [55]. To counteract chlorophyll interference with GFP detection, different methodologies have been developed for chlorophyll elimination in photosynthetic tissues, including exposure to alcohol [56], application of photobleaching herbicides [57] or use of gene silencing to suppress the Phytoene desaturase (PDS) gene
[58]. However, chlorophyll elimination treatments are notably harsh and demand additional manipulation of tissues, which may alter transgene expression, particularly expression of inducible DNA constructs.

GFP expression in soybean hairy roots was quite variable among different events containing the same promoter construct, although some general conclusions could be made about promoter strength using this validation tool. Similar to quantitative analysis of transient expression in lima bean cotyledonary tissue, the Gmubi3 and the Gmubi10 promoters also gave the highest and the lowest GFP intensity, respectively, in soybean hairy roots. The Gmubi1, Gmubi4, Gmubi7, Gmubi8 and Gmubi9 promoters showed quite similar GFP expression intensities using both validation tools. However, a comparison of transient and stable expression intensities using the Gmubi2, Gmubi5 and Gmubi6 promoters showed some inconsistencies in promoter strength using the two different validation tools (moderate, high and high transient expression but high, moderate and moderate expression in stably-transformed hairy roots, respectively;Table 3). The Gmubi2, Gmubi5 and Gmubi6 promoters may be the most interesting for further analysis as they show the greatest disparity in expression using transient and stable expression analyses.

The GFP intensities determined for GmERF promoters using hairy roots in general also correlated with the transient GFP levels determined using lima bean cotyledons. The GmERF2, GmERF3 and GmERF5 promoters were the most inconsistent expressers in this group (moderate, high and high transient GFP expression, but high, moderate and low GFP intensities in hairy roots, respectively; Table 3). Expression directed by these promoters may be affected by the wounding or other stresses caused by tissue manipulation and particle bombardment. Further studies on these 3 promoters in stably-transformed tissues may be of particular interest to identify regulatory regions within promoters that are responsive to various stimuli.

The transient expression system reported here differs considerably from the hairy root expression system,

Table 3 Grouping of the Gmubi and GmERF promoters based on the CaMV35S-driven GFP expression

\begin{tabular}{|c|c|c|c|c|c|c|}
\hline \multirow[b]{2}{*}{ Promoter } & \multicolumn{3}{|c|}{ Transient GFP expression } & \multicolumn{3}{|c|}{$\begin{array}{l}\text { GFP expression in hairy } \\
\text { roots }\end{array}$} \\
\hline & Low & Moderate & High & Low & Moderate & High \\
\hline Gmubi \# & 10 & 2,8 & $\begin{array}{l}1,3,4,5 \\
6,7,9\end{array}$ & 10 & $5,6,8$ & $\begin{array}{l}1,2,3,4 \\
7,9\end{array}$ \\
\hline GmERF \# & $\begin{array}{l}1,8, \\
9\end{array}$ & $2,4,7$ & $3,5,6,10$ & $\begin{array}{l}1,5 \\
8,9\end{array}$ & $3,4,7$ & $2,6,10$ \\
\hline
\end{tabular}

GFP levels driven by the CaMV35S promoter in both transient and hairy roots were considered as moderate. 
relative to the fate of the introduced DNA and the nature of the expressing tissue. Any consistency in expression intensity using the two validation tools, suggests a certain robustness in promoter activity. For transient expression using particle bombardment, large amounts of DNA are introduced [59] on each particle and cells that express the introduced DNA usually contain a particle in, or adjacent to the nucleus [60,61]. Transient expression results in a rapid increase in gene expression, followed by a rapid decline (Figure 4), which has been partly attributed to gene silencing of transient expression $[43,48]$. Therefore, during transient expression in lima bean cotyledonary cells, large amounts of plasmid DNA are delivered to the nucleus, which result in very high levels of extrachromosomal gene expression. Preintegrative, extrachromosomal DNAs may not be subject to the same regulatory influences as genomic DNA and this DNA may have different access to transcription factors. Nevertheless, transient expression might be a good early indicator of promoter strength in stably-transformed tissues [7].

Stably-expressed promoters that are introduced in soybean hairy roots are integrated into genomic DNA and expression in this tissue may more accurately reflect promoter activity in its native context. However, gene expression may also be affected by integration site and transgene copy number [62], as well as the status of the transgenic tissues. Although the soybean hairy root system may not be optimal for validation of some tissuespecific promoters, we have successfully used this system for validation of large number of promoters including promoters identified as "seed specific" (data not shown). Consistency in the intensity of gene expression using these two different validation tools suggests good stability and accurate prediction of relative promoter strengths.

\section{Southern hybridization analysis and transgene copy number}

GFP intensities were quite variable in independent primary hairy root events (Figure 6). This variation in gene expression across stably-transformed events has been often attributed to the site(s) of transgene insertion and transgene copy number [5,34]. The insertion site, copy number and structure of integrated DNA differs, depending on the transformation methods utilized. Direct transformation methods such as particle bombardment can frequently result in the insertion of large copy numbers of plasmid DNA at a single-site, leading to transgene silencing $[63,64]$. Gene cassettes or minimal constructs can reduce or eliminate this effect $[65,66]$. On the other hand, transformation using Agrobacterium typically results in lower copy number gene introductions, which has been reported to give more consistent transgene expression [63,64].
Our results suggest that the variability in $g f p$ gene expression in soybean hairy roots was associated with the copy number of the introduced T-DNA. The highest GFP expression levels were associated with roots that contained the highest copy numbers of introduced DNAs. Use of Agrobacterium tumefaciens for transformation usually results in the integration of single or low $\mathrm{T}$ DNA copies into the plant genome $[67,68]$. Although use of $A$. rhizogenes can lead to high copy T-DNA integration $[35,36,38]$, the relationship between high copy number integration and transgene expression has not been previously reported in hairy roots. Using Arabidopsis plants containing sequentially increasing copy numbers of a CaMV35S-driven $g f p$ gene, Schubert et al. [62] demonstrated increases in GFP expression levels when up to 4 copies of a CaMV35S-driven $g f p$ gene were present. As the copy number was increased to 5 and greater, GFP expression was suppressed. Schubert et al. [62] further suggested that suppression occurs once a gene expression threshold is reached and is gene-specific.

In this study, hairy roots containing up to 7 T-DNA inserts (Figure 7) displayed the highest GFP expression and did not show gene suppression. A significant correlation of high GFP expression with high copy number integration was observed with the GmERF6 and GmERF10 promoters (Additional file 4), both of which displayed higher expression levels than the CaMV35S promoter in soybean hairy roots (Figure 5b). If a threshold copy number/expression level is required to silence the $g f p$ gene, that threshold was not reached in the transgenic hairy roots.

The use of hairy roots to validate promoter activity is a simple alternative for gauging promoter strength in stably-transformed plants, although the influence of copy number on gene expression should be considered [69]. The transient expression analysis used in this research may nevertheless be more reflective of general promoter strength as each cell receives similar high copy numbers of each DNA construct, and hundreds to thousands of cells are collectively analyzed. As transient expression is analyzed prior to DNA integration, complications from conformational and positional effects in genomic DNA are avoided.

\section{Conclusions}

We report here the isolation and characterization of 20 novel soybean promoters from two different gene families, ubiquitin and ERF. A rapid quantitative evaluation of promoter strength was consistently performed in both transiently-expressing cotyledonary tissues of lima bean and stably-transformed hairy roots of soybean. We also provide novel insights towards the utilization of transient and stable expression systems for promoter validation. 


\section{Methods}

Phylogenetic analysis of the Gmubi and GmERF genes

The ubiquitin genes were identified in the soybean genome assembly (accessed in April, 2009; ftp://ftp.jgi-psf. org/pub/JGI_data/Glycine_max/Glyma1/annotation/) based on the presence of the highly conserved ubiquitincoding unit. The soybean ERF/AP2 genes were obtained from SoyDB: A Knowledge Database of Soybean Transcription Factors (http://casp.rnet.missouri.edu/soydb/) and verified using the Soybean Transcription Factor Knowledge Base (http://www.igece.org/Soybean_TF/).

The phylogenetic trees for Gmubi and GmERF gene families were constructed with the aligned amino acid sequences using MEGA 4.0 [70] and the Neighbor-Joining $(\mathrm{NJ})$ method [71]. For each gene family, the bootstrap consensus tree was inferred from 1000 replicates [72] and drawn to scale, with branch lengths in the same units as those of the evolutionary distances used to infer the phylogenetic tree. The evolutionary distances were computed using the Poisson correction method [73] and are in the units of the number of amino acid substitutions per site.

\section{DNA constructs}

For rapid direct cloning and subcloning of soybean promoters, a PUC19-derived expression vector (pFLEV; Finer Laboratory Expression Vector) was generated (Figure $8 \mathrm{a})$. For construction of pFLEV, a synthetic multiple cloning site (MCS) containing unique restriction sites and flanked by HindIII and either NcoI or SphI restriction sites was designed and introduced 5' to a $g f p$ gene encoding a soluble GFP [74]. The $g f p$ gene was succeeded by a nopaline synthase terminator (NOS) sequence. Additional restriction sites located at the 3' end of the $g f p$ sequence (BsrGI, NotI, StuI) and at the 3'
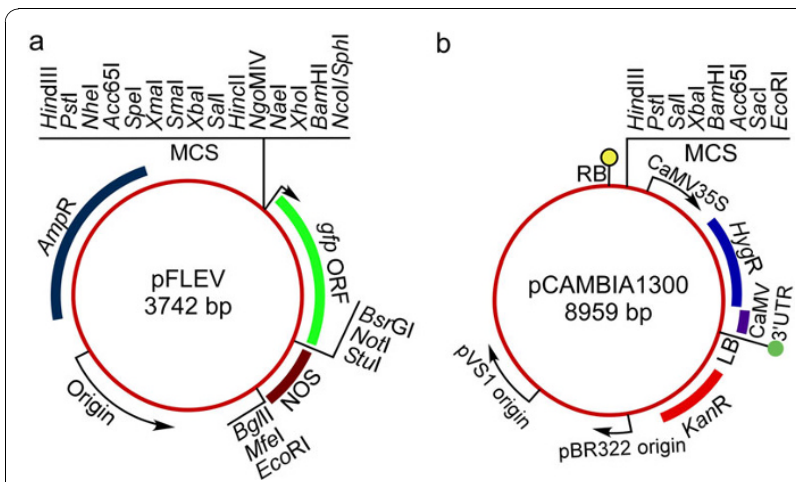

Figure 8 Expression vectors used for promoter cloning and functional assays. (a) Engineered PUC19-derived expression vector (pFLEV; Finer Laboratory Expression Vector), containing unique restriction sites for promoter cloning and manipulation. (b) pCAMBIA1300 vector used for hairy root production. MCS multiple cloning site, $R B$ right border, $L B$ left border. end of NOS (BglII, MfeI, EcoRI) were included in pFLEV to allow further mobilization of expression cassettes into different expression vectors.

The DNA sequences lying immediately upstream of the coding regions of 20 selected Gmubi and GmERF genes (Table 2) were PCR-amplified using specific primers (Additional file 5). Intronic regions (5' UTR) present in the coding sequences of Gmubi1-7 were also included in the 3' end of their respective cloned promoters. PCR-amplifications were conducted on genomic DNA from soybean (G. max 'Jack') using the FailSafe ${ }^{\text {тм }}$ PCR Kit (EPICENTRE ${ }^{\circledast}$ Biotechnologies, Madison, WI, USA). PCR products were purified, digested and inserted into the MCS of pFLEV (Figure 8a). All sequences of cloned promoters were confirmed by DNA sequencing. Promoter-containing pFLEV constructs were used for transient expression analysis in lima bean ( $P$. lunatus 'Henderson-Bush') cotyledons.

For construction of the binary version of the promoter constructs, the complete expression cassettes composed of promoter, $g f p$ coding sequence and NOS terminator were excised from pFLEV using appropriate restriction enzymes and cloned into the MCS of appropriately digested pCAMBIA1300 (CAMBIA, Canberra, Australia; Figure $8 \mathrm{~b}$ ). For soybean hairy root production, pCAMBIA1300-promoter constructs were introduced into $A$. rhizogenes strain K599 (kindly provided by Dr. Harold Trick, Kansas State University) by the freeze-thaw method [75].

\section{Transient expression analysis}

Soybean (G. max 'Jack') seeds were harvested from plants grown in the greenhouse $\left(16 / 8 \mathrm{~h}\right.$ light:dark, $\left.28^{\circ} \mathrm{C}\right)$ with supplemental lighting from high pressure sodium lamps. Lima bean seeds were harvested from plants grown in a growth chamber (50\% relative humidity, 16/ 8 h light:dark, $25 / 23^{\circ} \mathrm{C}$ day/night). Both soybean and lima bean seeds were surface sterilized in a $10 \%(\mathrm{v} / \mathrm{v})$ bleach solution with slow agitation for $20 \mathrm{~min}$, rinsed 47 times with sterile water and germinated between moistened sterile paper towels contained in GA7 culture vessels.

Transient expression was initially compared in soybean and lima bean cotyledons using a 35S-driven GFP construct [10] and a 35S-driven GFP::Hygromycin gene fusion (GFP::Hygromycin) [43]. Soybean and lima bean cotyledons were excised from 2-d-old and 4-d-old germinating seedlings, respectively. DNA constructs were precipitated onto tungsten particles and introduced into the adaxial surface of the cotyledons utilizing a Particle Inflow Gun [76]. Bombarded cotyledons were placed adaxial side up on OMS culture medium containing MS salts [77], B5 vitamins [78], 3\% sucrose and 0.2\% Gelrite ( $\mathrm{pH}$ 5.7) for GFP monitoring. Semi-continuous image 
acquisition was performed using an automated image collection system [8] composed of a MZFLIII dissecting microscope (Leica, Heerbrugg, Switzerland) equipped with a "GFP-2" filter set (Excitation $480 \pm 40$ nm, Emission $510 \mathrm{~nm}$ ), a Spot-RT CCD digital camera (Diagnostic Instruments Inc., Sterling Heights, MI, USA) and a robotics platform (Arrick Robotics Inc., Hurst, TX, USA). Soybean and lima bean cotyledons showing transient GFP expression were also examined $10 \mathrm{~h}$ post bombardment using a Leica TCS SP5 II confocal laser microscope (Leica, Heerbrugg, Switzerland). Based on the more consistent GFP expression patterns obtained using lima bean cotyledons, transient expression analysis of all 20 different cloned soybean promoters was conducted using lima bean cotyledons as the target tissue.

Quantitative analysis of transient GFP expression directed by the 20 novel soybean promoters in lima bean cotyledons was performed as previously described $[10,44]$. GFP expression levels for each promoter were calculated and presented as the percentage of the peak GFP expression of the CaMV35S promoter. For each promoter construct, 5 to 9 cotyledons were bombarded and monitored for $100 \mathrm{~h}$, over at least two independent experiments.

\section{Hairy root induction and analysis}

For induction of soybean hairy roots, cotyledons were inoculated as previously described [35] with some modifications. A. rhizogenes harboring the pCAMBIA1300promoter constructs was grown overnight in $2 \mathrm{ml}$ liquid YEP (Yeast Extract Peptone) medium containing 100 $\mathrm{mg} \mathrm{l}^{-1}$ kanamycin. A. rhizogenes without the binary vector was grown in YEP medium lacking antibiotics. Soybean (G. $\max$ 'Williams82') seeds were surface-sterilized and germinated in GA7 containers as described above. After $5 \mathrm{~d}$, cotyledons were excised and wounded several times on the abaxial side with a sterile scalpel dipped in the bacterial cultures. Inoculated cotyledons were cultured abaxial side up on P5 Fisherbrand ${ }^{\circ}$ (Fisher Scientific, Pittsburgh, PA, USA) filter paper moistened with sterile distilled water. After $3 \mathrm{~d}$, cotyledons were transferred to OMS medium containing $400 \mathrm{mg} \mathrm{l}^{-1}$ Timentin for hairy root induction. Cotyledons were incubated at $25^{\circ} \mathrm{C}$ with a $16: 8 \mathrm{~h}$ light:dark photoperiod under an illumination of $40 \mu \mathrm{Em}^{-2} \mathrm{~s}^{-1}$.

GFP-expressing hairy roots $(\sim 2 \mathrm{~cm})$ were excised from cotyledons and subcultured for $4 \mathrm{~d}$ on OMS medium containing $400 \mathrm{mg} \mathrm{l}^{-1}$ Timentin. Root tip regions were imaged utilizing the same microscope and camera used previously for transient GFP detection but the robotics components were disabled. Image analysis of roots was performed using ImageJ software [79]. High-resolution images $(1600 \times 1200$ pixels $)$ of individual root tips, $\sim 5 \mathrm{~mm}$ in length, were separated into red, blue and green channels and only the green channel data was used for quantification of GFP intensity. Due to the reflection of fluorescence through the culture medium next to GFP-expressing roots, the background gray value of a $100 \times 100$ pixel area adjacent to each root was first subtracted from every pixel present in this channel. The threshold levels were then adjusted to segment the expressing pixels from root images and the grayscale mean value of the background-corrected channel was then determined. An average grayscale mean value from the slight background fluorescence in the green channel from hairy roots induced with $A$. rhizogenes without the binary vector was also determined. GFP intensity for each root was calculated by subtracting the average grayscale means of roots induced with $A$. rhizogenes containing no binary vector from the grayscale means of the transgenic GFP-expressing hairy roots using the green channel. For each promoter construct, 14 to 32 independent hairy root events were analyzed, over at least two independent experiments. Statistical analysis was performed using SAS 9.2 TS (SAS Institute Inc., Cary, NC, USA).

\section{Southern hybridization analysis}

Southern blot analysis was performed using genomic DNA isolated from 18 transformed hairy root events containing the $g f p$ gene regulated by either the GmERF6 or GmERF10 promoter. Genomic DNA was extracted from lyophilized root tissues according to Murray and Thompson [80] as modified by Fulton et al. [81]. DNAs from each independent root event $(10 \mu \mathrm{g})$ were digested overnight with $B s r \mathrm{GI}$, which cuts the T-DNA harboring the GmERF6 or GmERF10 promoter at a single site, only 10 bp from the 3 ' end of the $g f p$ gene. Digested DNAs were separated on $0.8 \%(\mathrm{w} / \mathrm{v})$ agarose gels and then transferred to nylon membranes (Roche Diagnostics GmbH, Indianapolis, IN, USA) as described by Sambrook et al. [82]. The hybridization probe was a $717 \mathrm{bp}$ fragment of the $g f p$ coding region amplified by PCR using the primers 5'ATGGTGAGCAAGGGCGAGGAGCTG3' and 5'TTACTTGTACAGCTCGTCCATG3'. The probe was labeled with $\left[\alpha-{ }^{32} \mathrm{P}\right]$-dCTP (PerkinElmer, Boston, MA, USA) using the Prime-It ${ }^{\circ}$ II Random Labeling Kit (Stratagene, La Jolla, CA, USA) according to the manufacturer's instructions. The labeled probe was hybridized to the membranes and incubated overnight at $60^{\circ} \mathrm{C}$. The hybridized membranes were exposed to a phosphor screen holder for $24 \mathrm{~h}$ and then scanned with a Storm 860 PhosphorImager ${ }^{\mathrm{rm}}$ System (Molecular Dynamics, Sunnyvale, CA, USA) for visualization of hybridization patterns. 


\section{Additional material}

Additional file 1: List of predicted amino acid sequences used for the phylogenetic analysis of the Gmubi genes. The Gmubi genes were identified in the soybean genome assembly (accessed in April, 2009; ftp://ftp.jgi-psf.org/pub/JGI_data/Glycine_max/Glyma1/annotation/) based on the presence of the highly conserved ubiquitin-coding unit.

Additional file 2: List of AP2 domains used for the phylogenetic analysis of the GmERF genes. The soybean GMERF genes were obtained from SoyDB: A Knowledge Database of Soybean Transcription Factors (http://casp.rnet.missouri.edu/soydb/) and verified using the Soybean Transcription Factor Knowledge Base (http://www.igece.org/ Soybean_TF/).

Additional file 3: A time-lapse animation of soybean and lima bean cotyledons transformed with the 35S-GFP construct. Images were collected every hour for $100 \mathrm{~h}$ using an automated image collection system and assembled using ImageReady.

Additional file 4: Regression analysis of GFP expression and transgene copy number scored on the Southern blots. GFP expression for each hairy root shown on Figure 7 was quantified and grayscale values correlated with the respective transgene copy number. The regression analysis showed P-Values of 0.005 and 0.039 for GmERF6and GmERF10-containing hairy roots, respectively.

Additional file 5: List of primer sequences used to PCR-amplify the soybean promoters. Restriction sites incorporated in the forward and reverse primers are underlined. $F$ forward primer, $R$ reverse primer.

\section{List of abbreviations}

CaMV35S: Cauliflower Mosaic Virus 35S; MS: Murashige and Skoog; OMS: MS medium containing no plant growth regulators; ERF: Ethylene Response Factor; Gmubi: Glycine max Ubiquitin; GmERF: Glycine max Ethylene Response Factōr; 5' UTR: 5' Untranslated Regioñ; pFLEV̄: Finer Laboratory Expression Vector; MCS: Multiple Cloning Site; PCR: Polymenerasē Chain Reaction.

\section{Acknowledgements}

We would like to thank Dr. Tea Meulia (MCIC/OARDC/OSU) for the technical assistance with confocal microscopy. We also thank Drs. Eric Stockinger and Leah McHale for the critical reading of this manuscript. Salaries and research support were provided by the United Soybean Board, and by State and Federal funds appropriated to The Ohio State University/Ohio Agricultural Research and Development Center. This research was partially supported by a fellowship from CONACYT, Mexico, to CMHG. Mention of trademark or proprietary products does not constitute a guarantee or warranty of the product by OSU/OARDC and also does not imply approval to the exclusion of other products that may also be suitable. Journal Article No HCS 10-09.

\section{Author details}

'Department of Horticulture and Crop Science, OARDC/The Ohio State University, 1680 Madison Ave., Wooster, OH 44691 USA. ${ }^{2}$ Department of Biology, University of Virginia, Charlottesville, VA 22904 USA. ${ }^{3}$ Department of Microbiology, University of Virginia Health Systems, Charlottesville, VA 22908 USA. ${ }^{4}$ Department of Biology and Microbiology, South Dakota State University, Brookings, SD 57007 USA. ${ }^{5}$ USACE, Environmental Lab, ERDC, 3909 Halls Ferry Road, Vicksburg, MS 39180 USA.

\section{Authors' contributions}

CMHG cloned the GmERF promoters, developed and optimized the transient expression and hairy root validation tools, designed experiments, collected and analyzed data for GmERF promoters, and drafted the manuscript. RAB cloned the Gmubi promoters and collected data for Gmubi-mediated expression in transient expression and hairy roots. PJR performed the phylogenetic analysis of Gmubi and GmERF gene families. MLJ contributed to the interpretation of gene expression analysis in hairy roots and critically revised the manuscript. XC identified the Gmubi and GmERF gene families in the soybean genome and transcription factor databases. MPT assisted with
Gmubi promoter identification and critically revised the manuscript. JJF was the principal investigator, conceived of the experiments and contributed to project design, isolation of the Gmubi promoters, data analysis, and manuscript drafting. All authors read and approved the final manuscript.

Received: 23 June 2010 Accepted: 4 November 2010

Published: 4 November 2010

\section{References}

1. Schnable PS, Ware D, Fulton RS, Stein JC, Wei F, Pasternak S, Liang C, Zhang J, Fulton L, Graves TA, Minx P, Reily AD, Courtney L, Kruchowski SS, Tomlinson C, Strong C, Delehaunty K, Fronick C, Courtney B, Rock SM, Belter E, Du F, Kim K, Abbott RM, Cotton M, Levy A, Marchetto P, Ochoa K, Jackson SM, Gillam B, et al: The B73 maize genome: complexity, diversity, and dynamics. Science 2009, 326:1112-1115.

2. Paterson AH, Bowers JE, Bruggmann R, Dubchak I, Grimwood J, Gundlach H, Haberer G, Hellsten U, Mitros T, Poliakov A, Schmutz J, Spannagl M, Tang H, Wang X, Wicker T, Bharti AK, Chapman J, Feltus FA, Gowik U, Grigoriev IV, Lyons E, Maher CA, Martis M, Narechania A, Otillar RP, Penning BW, Salamov AA, Wang Y, Zhang L, Carpita NC, et al: The Sorghum bicolor genome and the diversification of grasses. Nature 2009, 457:551-556.

3. Schmutz J, Cannon SB, Schlueter J, Ma J, Mitros T, Nelson W, Hyten DL, Song Q, Thelen JJ, Cheng J, Xu D, Hellsten U, May GD, Yu Y, Sakurai T, Umezawa T, Bhattacharyya MK, Sandhu D, Valliyodan B, Lindquist E, Peto M, Grant D, Shu S, Goodstein D, Barry K, Futrell-Griggs M, Abernathy B, Du J, Tian Z, Zhu L, et al: Genome sequence of the palaeopolyploid soybean. Nature 2010, 463:178-183.

4. Potenza C, Aleman L, Sengupta-Gopalan C: Targeting transgene expression in research, agricultural, and environmental applications: Promoters used in plant transformation. In Vitro Cell Dev Biol Plant 2004, 40:1-22.

5. Butaye KMJ, Cammue BPA, Delauré SL, De Bolle MFC: Approaches to minimize variation of transgene expression in plants. Mol Breed 2005, 16:79-91.

6. Rushton PJ, Reinstadler A, Lipka V, Lippok B, Somssich IE: Synthetic plant promoters containing defined regulatory elements provide novel insights into pathogen- and wound-induced signaling. Plant Cell 2002, 14:749-762.

7. Hernandez-Garcia CM, Martinelli AP, Bouchard RA, Finer JJ: A soybean (Glycine max) polyubiquitin promoter gives strong constitutive expression in transgenic soybean. Plant Cell Rep 2009, 28:837-849.

8. Buenrostro-Nava MT, Ling PP, Finer JJ: Comparative analysis of $35 \mathrm{~S}$ and lectin promoters in transgenic soybean tissue using an automated image acquisition system and image analysis. Plant Cell Rep 2006, 25:920-926.

9. Thirkettle-Watts D, McCabe TC, Clifton R, Moore C, Finnegan PM, Day DA, Whelan J: Analysis of the alternative oxidase promoters from soybean. Plant Physiol 2003, 133:1158-1169.

10. Chiera JM, Bouchard RA, Dorsey SL, Park E, Buenrostro-Nava MT, Ling PP Finer JJ: Isolation of two highly active soybean (Glycine max (L.) Merr.) promoters and their characterization using a new automated image collection and analysis system. Plant Cell Rep 2007, 26:1501-1509.

11. Wang J, Oard JH: Rice ubiquitin promoters: deletion analysis and potential usefulness in plant transformation systems. Plant Cell Rep 2003, 22:129-134.

12. Christensen AH, Quail PH: Ubiquitin promoter-based vectors for highlevel expression of selectable and/or screenable marker genes in monocotyledonous plants. Transgenic Res 1996, 5:213-218.

13. Plesse B, Criqui M-C, Durr A, Parmentier Y, Fleck J, Genschik P: Effects of the polyubiquitin gene Ubi.U4 leader intron and first ubiquitin monomer on reporter gene expression in Nicotiana tabacum. Plant Mol Biol 2001, 45:655-667.

14. Le Hir $H$, Nott $A$, Moore MJ: How introns influence and enhance eukaryotic gene expression. Trends Biochem Sci 2003, 28:215-220

15. Binet MN, Lepetit $M$, Weil JH, Tessier LH: Analysis of a sunflower polyubiquitin promoter by transient expression. Plant Sci 1991, 79:87-94.

16. Garbarino JE, Oosumi T, Belknap WR: Isolation of a polyubiquitin promoter and its expression in transgenic potato plants. Plant Physiol 1995, 109:1371-1378. 
17. Rollfink IK, Silber MV, Pfitzner UM: Characterization and expression of a heptaubiquitin gene from tomato. Gene 1998, 211:267-276.

18. Mochida K, Yoshida T, Sakurai T, Yamaguchi-Shinozaki K, Shinozaki K, Tran LSP: In silico analysis of transcription factor repertoire and prediction of stress responsive transcription factors in soybean. DNA Res 2009, 16:353-369.

19. Nakano T, Suzuki K, Fujimura T, Shinshi H: Genome-wide analysis of the ERF gene family in Arabidopsis and rice. Plant Physiol 2006, 140:411-432.

20. Ohme-Takagi M, Shinshi H: Ethylene-inducible DNA binding proteins that interact with an ethylene-responsive element. The Plant Cell 1995, 7:173-182.

21. Onate-Sanchez L, Singh KB: Identification of Arabidopsis ethyleneresponsive element binding factors with distinct induction kinetics after pathogen infection. Plant Physiol 2002, 128:1313-1322.

22. Stockinger EJ, Gilmour SJ, Thomashow MF: Arabidopsis thaliana CBF1 encodes an AP2 domain-containing transcriptional activator that binds to the C-repeat/DRE, a cis-acting DNA regulatory element that stimulates transcription in response to low temperature and water deficit. Proc Natl Acad Sci USA 1997, 94:1035-1040.

23. Zhang $G$, Chen $M, L i L, X u Z$, Chen $X$, Guo J, Ma Y: Overexpression of the soybean GmERF3 gene, an AP2/ERF type transcription factor for increased tolerances to salt, drought, and diseases in transgenic tobacco. J Exp Bot 2009, 60:3781-3796.

24. Hinchee MAW, Connor-Ward DV, Newell CA, McDonnell RE, Sato SJ, Gasser CS, Fischhoff DA, Re DB, Fraley RT, Horsch RB: Production of transgenic soybean plants using Agrobacterium-mediated DNA transfer. Nat Biotech 1988, 6:915-922.

25. McCabe DE, Swain WF, Martinell BJ, Christou P: Stable transformation of soybean (Glycine max) by particle acceleration. Nat Biotech 1988, 6:923-926.

26. Finer JJ, McMullen MD: Transformation of soybean via particle bombardment of embryogenic suspension culture tissue. In Vitro Cell Dev Biol Plant 1991, 27:175-182.

27. Finer JJ, Larkin KM: Genetic transformation of soybean using particle bombardment and SAAT approaches. In Handbook of new technologies for genetic improvement of legumes. Edited by: Kirti P. Boca Raton, Florida CRC Press; 2008:103-125.

28. Mirabella R, Martirani L, Lamberti A, laccarino M, Chiurazzi M: The soybean $E N O D 40(2)$ promoter is active in Arabidopsis thaliana and is temporally and spatially regulated. Plant Mol Biol 1999, 39:177-181.

29. Chamberland S, Daigle N, Bernier F: The legumin boxes and the $3^{\prime}$ part of a soybean $\beta$-conglycinin promoter are involved in seed gene expression in transgenic tobacco plants. Plant Mol Biol 1992, 19:937-949.

30. Joung $\mathrm{YH}$, Kamo K: Expression of a polyubiquitin promoter isolated from Gladiolus. Plant Cell Rep 2006, 25:1081-1088

31. Furtado A, Henry RJ, Takaiwa F: Comparison of promoters in transgenic rice. Plant Biotech J 2008, 6:679-693.

32. Kamo K, Blowers A, Smith F, Van Eck J, Lawson R: Stable transformation of Gladiolus using suspension cells and callus. J Am Soc Hortic Sci 1995, 120:347-352.

33. Ponappa T, Brzozowski AE, Finer JJ: Transient expression and stable transformation of soybean using the jellyfish green fluorescent protein. Plant Cell Rep 1999, 19:6-12.

34. Finer JJ: Plant nuclear transformation. In Genetic modification of plants, Biotechnology in Agriculture and Forestry. Edited by: Kempken F, Jung C. Berlin Heidelberg, vol 64: Springer-Verlag; 2010:3-21.

35. Cho H-J, Farrand SK, Noel GR, Widholm JM: High-efficiency induction of soybean hairy roots and propagation of the soybean cyst nematode. Planta 2000, 210:195-204

36. Cho HJ, Brotherton JE, Widholm JM: Use of the tobacco feedbackinsensitive anthranilate synthase gene (ASA2) as a selectable marker for legume hairy root transformation. Plant Cell Rep 2004, 23:104-113.

37. Lozovaya W, Lygin AV, Zernova OV, Ulanov AV, Li S, Hartman GV, Widholm JM: Modification of phenolic metabolism in soybean hairy roots through down regulation of chalcone synthase or isoflavone synthase. Planta 2007, 225:665-679.

38. Collier R, Fuchs B, Walter N, Lutke WK, Taylor CG: Ex vitro composite plants: an inexpensive, rapid method for root biology. Plant J 2005, 43:449-457.

39. Li J, Todd TC, Trick HN: Rapid in planta evaluation of root expressed transgenes in chimeric soybean plants. Plant Cell Rep 2010, 29:113-123.
40. Thress K, Henzel W, Shillinglaw W, Kornbluth S: Scythe: a novel reaperbinding apoptotic regulator. EMBO J 1998, 17:6135-6143.

41. Kim I, Mi K, Rao H: Multiple interactions of Rad23 suggest a mechanism for ubiquitylated substrate delivery important in proteolysis. Mol Biol Cell 2004, 15:3357-3365.

42. Rushton PJ, Bokowiec MT, Han S, Zhang H, Brannock JF, Chen X, Laudeman TW, Timko MP: Tobacco transcription factors: novel insights into transcriptional regulation in the solanaceae. Plant Physiol 2008, 147:280-295.

43. Chiera JM, Lindbo JA, Finer JJ: Quantification and extension of transient GFP expression by the co-introduction of a suppressor of silencing. Transgenic Res 2008, 17:1143-1154.

44. Hernandez-Garcia CM, Chiera JM, Finer JJ: Robotics and dynamic image analysis for studies of gene expression in plant tissues. J Vis Exp 2010, 39 [http://www.jove.com/index/details.stp?id=1733].

45. Severin A, Woody J, Bolon Y-T, Joseph B, Diers B, Farmer A, Muehlbauer G, Nelson R, Grant D, Specht J, Graham M, Cannon S, May G, Vance C, Shoemaker R: RNA-Seq Atlas of Glycine max: A guide to the soybean transcriptome. BMC Plant Biol 2010, 10:160.

46. Libault M, Farmer A, Joshi T, Takahashi K, Langley RJ, Franklin LD, He J, Xu D, May G, Stacey G: An integrated transcriptome atlas of the crop model (Glycine max) and its use in comparative analyses in plants. Plant J 2010, 63:86-99.

47. Zhang G, Chen M, Chen X, Xu Z, Guan S, Li L-C, Li A, Guo J, Mao L, Ma Y: Phylogeny, gene structures, and expression patterns of the ERF gene family in soybean (Glycine max L.). J Exp Bot 2008, 59:4095-4107.

48. Dhillon T, Chiera JM, Lindbo JA, Finer JJ: Quantitative evaluation of six different viral suppressors of silencing using image analysis of transient GFP expression. Plant Cell Rep 2009, 28:639-647.

49. Klein TM, Harper EC, Svab Z, Sanford JC, Fromm ME, Maliga P: Stable genetic transformation of intact Nicotiana cells by the particle bombardment process. Proc Natl Acad Sci USA 1988, 85:8502-8505.

50. Sullivan JA, Shirasu K, Deng XW: The diverse roles of ubiquitin and the $26 \mathrm{~S}$ proteasome in the life of plants. Nat Rev Genet 2003, 4:948-958.

51. Sivamani E, Qu R: Expression enhancement of a rice polyubiquitin gene promoter. Plant Mol Biol 2006, 60:225-239.

52. Lu J, Sivamani E, Azhakanandam K, Samadder P, Li X, Qu R: Gene expression enhancement mediated by the $5^{\prime}$ UTR intron of the rice rubi3 gene varied remarkably among tissues in transgenic rice plants. Mol Genet Genomics 2008, 279:563-572.

53. Yamaguchi-Shinozaki K, Shinozaki K: Organization of cis-acting regulatory elements in osmotic- and cold-stress-responsive promoters. Trends Plant Sci 2005, 10:88-94.

54. Chilton M-D, Tepfer DA, Petit A, David C, Casse-Delbart F, Tempe J: Agrobacterium rhizogenes inserts T-DNA into the genomes of the host plant root cells. Nature 1982, 295:432-434.

55. Billinton N, Knight AW: Seeing the wood through the trees: A review of techniques for distinguishing Green Fluorescent Protein from endogenous autofluorescence. Anal Biochem 2001, 291:175-197.

56. Zhou X, Carranco R, Vitha S, Hall TC: The dark side of green fluorescent protein. New Phytol 2005, 168:313-322.

57. Wu C, Chiera JM, Ling PP, Finer JJ: Isoxaflutole treatment leads to reversible tissue bleaching and allows for more effective detection of GFP in transgenic soybean tissues. In Vitro Cell Dev Biol Plant 2008, 44:540-547.

58. Zhang L, Gase K, Baldwin IT, Gális I: Enhanced fluorescence imaging in chlorophyll-suppressed tobacco tissues using virus-induced gene silencing of the phytoene desaturase gene. Biotechniques 2010, 48:125-133.

59. Hadi MZ, McMullen MD, Finer JJ: Transformation of 12 different plasmids into soybean via particle bombardment. Plant Cell Rep 1996, 15:500-505.

60. Yamashita T, lida A, Morikawa H: Evidence that more than $90 \%$ of $\beta$ Glucuronidase-expressing cells after particle bombardment directly receive the foreign gene in their nucleus. Plant Physiol 1991, 97:829-831.

61. Hunold R, Bronner R, Hahne G: Early events in microprojectile bombardment: cell viability and particle location. Plant J 1994, 5:593-604.

62. Schubert D, Lechtenberg B, Forsbach A, Gils M, Bahadur S, Schmidt R: Silencing in Arabidopsis T-DNA transformants: the predominant role of a gene-specific RNA sensing mechanism versus position effects. Plant Cell 2004, 16:2561-2572. 
63. Shou H, Frame BR, Whitham SA, Wang K: Assessment of transgenic maize events produced by particle bombardment or Agrobacterium-mediated transformation. Mol Breed 2004, 13:201-208.

64. Dai S, Zheng P, Marmey P, Zhang S, Tian W, Chen S, Beachy RN, Fauquet C: Comparative analysis of transgenic rice plants obtained by Agrobacterium-mediated transformation and particle bombardment. $\mathrm{Mol}$ Breed 2001, 7:25-33.

65. Fu X, Duc LT, Fontana S, Bong BB, Tinjuangjun P, Sudhakar D, Twyman RM, Christou P, Kohli A: Linear transgene constructs lacking vector backbone sequences generate low-copy-number transgenic plants with simple integration patterns. Transgenic Res 2000, 9:11-19.

66. Agrawal PK, Kohli A, Twyman RM, Christou P: Transformation of plants with multiple cassettes generates simple transgene integration patterns and high expression levels. Mol Breed 2005, 16:247-260.

67. Ishida Y, Saito H, Ohta S, Hiei Y, Komari T, Kumashiro T: High efficiency transformation of maize (Zea mays L.) mediated by Agrobacterium tumefaciens. Nat Biotech 1996, 14:745-750

68. Zhao Z-y, Cai T, Tagliani L, Miller M, Wang N, Pang H, Rudert M, Schroeder S, Hondred D, Seltzer J, Pierce D: Agrobacterium-mediated sorghum transformation. Plant Mol Biol 2000, 44:789-798.

69. Gupta M, Nirunsuksiri W, Schulenberg G, Hart T, Novak S, Bryan J, Vanopdorp N, Bing J, Thompson S: A non-PCR-based Invader ${ }^{\circledR}$ assay quantitatively detects single-copy genes in complex plant genomes. $\mathrm{Mol}$ Breed 2008, 21:173-181.

70. Tamura K, Dudley J, Nei M, Kumar S: MEGA4: Molecular Evolutionary Genetics Analysis (MEGA) Software Version 4.0. Mol Biol Evol 2007, 24:1596-1599.

71. Saitou N, Nei M: The neighbor-joining method: a new method for reconstructing phylogenetic trees. Mol Biol Evol 1987, 4:406-425.

72. Felsenstein J: Confidence limits on phylogenies: an approach using the bootstrap. Evolution 1985, 39:783-791.

73. Zuckerkandl E, Pauling L, Bryson V, Vogel HJ: Evolutionary divergence and convergence in proteins. Evolving Genes and Proteins New York: Academic Press; 1965, 97-166.

74. Chiu W-I, Niwa Y, Zeng W, Hirano T, Kobayashi H, Sheen J: Engineered GFP as a vital reporter in plants. Curr Biol 1996, 6:325-330.

75. Chen H, Nelson RS, Sherwood JL: Enhanced recovery of transformants of Agrobacterium tumefaciens after freeze-thaw transformation and drug selection. Biotechniques 1994, 16:664-670.

76. Finer JJ, Vain P, Jones MW, McMullen MD: Development of the particle inflow gun for DNA delivery to plant cells. Plant Cell Rep 1992, 11:323-328.

77. Murashige T, Skoog F: A revised medium for rapid growth and bio assays with tobacco tissue cultures. Physiol Plant 1962, 15:473-497.

78. Gamborg OL, Miller RA, Ojima K: Nutrient requirements of suspension cultures of soybean root cells. Exp Cell Res 1968, 50:151-158.

79. Rasband W: ImageJ, U. S. National Institutes of Health, Bethesda, Maryland, USA. 1997 [http://rsbweb.nih.gov/ij/].

80. Murray MG, Thompson WF: Rapid isolation of high molecular weight plant DNA. Nucleic Acids Res 1980, 8:4321-4326.

81. Fulton T, Chunwongse J, Tanksley S: Microprep protocol for extraction of DNA from tomato and other herbaceous plants. Plant Mol Biol Rep 1995, 13:207-209.

82. Sambrook J, Fritsch EF, Maniatis T: Molecular Cloning: A Laboratory Manual. Cold Spring Harbor, NY: Cold Spring Harbor Laboratory; 21989.

doi:10.1186/1471-2229-10-237

Cite this article as: Hernandez-Garcia et al: High level transgenic expression of soybean (Glycine max) GmERF and Gmubi gene promoters isolated by a novel promoter analysis pipeline. BMC Plant Biology 2010 10:237.

\section{Submit your next manuscript to BioMed Central and take full advantage of:}

- Convenient online submission

- Thorough peer review

- No space constraints or color figure charges

- Immediate publication on acceptance

- Inclusion in PubMed, CAS, Scopus and Google Scholar

- Research which is freely available for redistribution

Submit your manuscript at www.biomedcentral.com/submit 